monográfico: Trasplante Renal. Experiencia del Hospital Clínico de Barcelona

Arch. Esp. Urol., 58, 6 (537-542), 2005

\title{
RESULTADOS A LARGO PLAZO DEL TRASPLANTE RENAL DE DONANTE VIVO: SUPERVIVENCIA DE INJ ERTO Y RECEPTOR.
}

\author{
M arta C respo Barrio, N uria Esforzado Armengol, Maria José Ricart Brulles y Federico \\ O ppenheimer Salinas.
}

Servicio de N efrología. Unidad Trasplante Renal. Hospital Clínico de Barcelona. España

\begin{abstract}
Resumen.- Los resultados en la supervivencia del injerto y del paciente en el trasplante renal de donante vivo son superiores a los obtenidos en el trasplante renal de donante cadáver. En España, el trasplante renal de vivo apenas supone el $1 \%$ de la actividad total frente al $60 \%$ en Estados Unidos. De acuerdo con la literatura, la experiencia de la Unidad de Trasplante Renal del Hospital Clinic de Barcelona ha demostrado una mejor supervivencia de injerto y receptor en el grupo de receptores de injertos de donante vivo. El análisis de 184 trasplantes renales de donante vivo y 1678 trasplantes renales de donante cadáver realizados entre los años 1978 y 2002 mostró que la supervivencia del injerto fue superior en el grupo de donan-
\end{abstract}

N uria Esforzado

Servicio de N efrología

Hospital C línico de Barcelona

C/ Villarroel, 170

08036 Barcelona. (España) te vivo $(p<0.01)$. A su vez, la supervivencia del injerto resultó claramente mejor en los receptores de un injerto de donante vivo HLA idéntico $(n=38)$ en comparación con los receptores de un injerto HLA haploidéntico $(n=142)(p<0.05)$. La introducción de más y mejores fármacos inmunosupresores, así como un mejor manejo diagnóstico y terapéutico del rechazo agudo, la profilaxis infecciosa y el control de las complicaciones han contribuido a una mejoría en los resultados del trasplante. Asimismo, con el paso de los años se ha ido reduciendo de forma considerable la incidencia de rechazo agudo. Entre los años 1978 y 1983 la ausencia de rechazo agudo fue del $45,1 \%$, entre los años 1984 y 1998 del $57,3 \%$, y del 84,7\% entre los años 1999 y 2003.

En conclusión, estos resultados demuestran una mejor supervivencia de los injertos y receptores de trasplante renal de donante vivo en comparación con los receptores de donante cadáver, así como el bajo riesgo que supone para el donante, deben incentivar a las autoridades, a los profesionales y a los pacientes a promocionar esta alternativa terapéutica mediante una información adecuada con mayor difusión. El trasplante renal de donante vivo debe contribuir junto con el trasplante de cadáver, puesto que no son opciones excluyentes, a paliar nuestras largas listas de espera..

Palabras clave: Trasplante renal donante vivo. Supervivencia del injerto.Supervivencia del paciente. 
Summary.- Donor kidney transplantation's graft and patient survivals are better than cadaver donor's. In Spain, living donor kidney transplantation hardly accounts for $1 \%$ of transplant activity in comparison to $60 \%$ in United States. Accordingly to bibliography, the experience of the Renal Transplant Unit of the Hospital Clinic de Barcelona has demonstrated better graft and receptor survival for living donor recipients. The analysis of 184 living donor kidney transplants and 1678 cadaver donor transplants performed between 1978 and 2002 showed that graft survival was higher in the group of living donors $(p<0.01)$. At the same time, graft survival was clearly better in receptors of HLA haploidentical grafts $(n=142)(p<0.05)$. The introduction of new and better immunosuppressive drugs, as well as better diagnostic and therapeutic management of acute rejection, prophylaxis for infections, and control of complications have contributed to better results. The absence of acute rejection between 1978 and 1983 was $45.1 \%$, between 1984 and 1998 was $57.3 \%$ and $84.7 \%$ between 1999 and 2003.

In conclusion, these results demonstrate better graft and patient survival for living donor kidney transplants in comparison with cadaver donor receptors. Altogether with the low risk involved for donors should incentivate authorities, professionals, and patients to promote these therapeutic option by means of adequate information and wider diffusion. Living donor kidney transplantation should contribute together with cadaver kidney transplantation to lessen our long waiting lists, because they are not excluding options.

Keywords: Living donor kidney transplantation.

$G$ raft survival. Patient survival.

\section{INTRODUCCIÓN}

La razón más frecuentemente esgrimida para justificar el trasplante renal procedente de donante vivo es la escasez de donantes cadáveres, que contribuye a perpetuar las listas de espera (1-3). La razón de mayor peso debe ser, sin embargo, que se trata de la mejor opción terapéutica para el tratamiento de la insuficiencia renal crónica. El trasplante renal de donante vivo ofrece claras ventajas sobre el trasplante de donante cadáver. Permite con frecuencia disminuir la morbilidad y la problemática socio-laboral o familiar asociadas a la insuficiencia renal crónica al tra- tarse de una alternativa de tratamiento programable, que puede, por tanto, realizarse antes de tener que iniciar el tratamiento sustitutivo con diálisis. El trasplante renal de donante vivo ofrece unos resultados significativamente mejores que el de cadáver con una mayor supervivencia del injerto y del paciente. Por todo ello, las Guías Europeas de trasplante renal recomiendan la utilización de injertos renales de donante vivo, siempre que sea posible (4).

\section{Supervivencia del injerto y del paciente}

Existen evidencias que indican que la función retrasada del injerto renal $(5,6)$ y el rechazo agudo (7) pueden influir negativamente a corto y a largo plazo en la supervivencia del injerto. Es obvio que el riesgo de retraso en la recuperación de la función del injerto es menor en los injertos procedentes de donante vivo, porque habitualmente la isquemia fría en estos casos es prácticamente inexistente. El análisis de los datos de la base de UNOS correspondientes a los a ños 1991-2000 situó la necesidad de diálisis durante la primera semana en $5 \%$ en los receptores de injertos de donante vivo frente a un $23 \%$ en los receptores de donante cadáver, así como la existencia de anuria el primer día postrasplante en $5 \%$ en los injertos de donante vivo y en $16 \%$ en los de cadáver en el año 2000 (8). Según algunos autores el riesgo de rechazo agudo es también menor en los trasplantes renales de donante vivo, tanto si se trata de injertos de donantes genéticamente relacionados como de no relacionados. Esto podría ser debido a que la muerte encefálica desencadena una serie de mecanismos infla matorios inespecíficos que aumentan la intensidad de la respuesta inmunológica aguda del receptor después del trasplante (9). Sin embargo, no existen datos que avalen una menor incidencia de rechazo agudo en los trasplantes de donante vivo no idéntico.

Por estos y otros motivos, los resultados en la supervivencia del injerto y del paciente en el trasplante renal de donante vivo son superiores a los obtenidos en el trasplante renal de donante cadáver (Tabla I).

Partiendo de los datos del registro UNOS de más de 45.000 trasplantes renales, Cecka mostró que la supervivencia estimada del injerto a los 10 años para los trasplantes realizados entre 1988 y 2000 era del $53-57 \%$ para los trasplantes de donantes vivos 
frente al 38\% para los trasplantes de donantes cadáver (1). En consonancia con lo anterior, las experiencias de diversos centros han demostrado con números menores hallazgos semejantes. En el estudio de Go y col., que incluyó 91 trasplantes renales realizados entre enero de 1993 y junio de 2003, $36(39,6 \%)$ procedentes de donantes vivos y $55(60,4 \%)$ de donantes cadáveres, la supervivencia del injerto a los 2, 5 y 10 a ños para los injertos de donante vivo fue de $96,9 \%$, $85,6 \%$ y $62,3 \%$, y de $89,9 \%, 71,3 \%$ y $35 \%$ para los injertos de donante cadáver (10). A su vez, Kim y col. en una revisión de 421 trasplantes renales realizados en Corea entre febrero de 1995 y diciembre de 2001, 216 de donante vivo y 205 de donante cadáver, hallaron una supervivencia del injerto de donante vivo a los 5 años superior a la de cadáver $(91,7$ vs. $87,3 \%$, $p=0.0234$ ), pero no encontraron diferencias en la supervivencia del paciente en ambos grupos (11).

Factores como la ausencia de rechazo, el sexo femenino de donante y de receptor, la edad del receptor ( $>14$ años) y la creatinina del donante inferior a $2,5 \mathrm{mg} / \mathrm{dl}$ en el momento del trasplante se asociaron significativamente a una mejor supervivencia del injerto a los 5 años en el trasplante de cadáver, mientras que sólo la edad del receptor (>14 años) y la ausencia de rechazo influyeron de forma significativa en la supervivencia del injerto en el trasplante de donante vivo. En el análisis multivariante el único factor pronóstico de la supervivencia del injerto fue la existencia de rechazo, tanto en el grupo de donante vivo como en el de donante cadáver. En ambos grupos, factores como la edad del donante y del receptor, el tipo de diálisis, la compatibilidad ABO y HLA, el tiempo de isquemia fría, el tipo de inmunosupresión y la infección por CM V no ejercieron una influencia significativa en la supervivencia del injerto (11).

Por su parte, Kwon y col. evaluaron la importancia de la masa renal trasplantada en 614 casos de donante vivo realizados entre 1979 y 2002 (12). Encontraron una supervivencia global de 92,6\%, $82,3 \%$ y $76,07 \%$ a 1,5 y 10 años respectivamente. Los principales parámetros que se asociaron con la supervivencia del injerto fueron la edad del donante $(p=0.0000)$, la existencia de rechazo $(p=0.0000)$, el sexo del donante $(p=0.0215)$ y la compatibilidad HLA$D R(p=0.0516)$. La supervivencia actuarial del injerto

TABLA I.- SUPERVIVEN CIA CO M PARADA DE IN JERTO S REN ALES PRO CEDEN TES DE DO N AN TES VIVO SO CADÁ VERES Y RECEPTO RES SEG ÚN DISTIN TO S REG ISTRO S.

$E T=$ Eurotrasplant (registro obligatorio de la actividad de trasplante en Holanda, Bélgica, Luxemburgo, Alemania, Austria y Eslovenia)

CTS = Collaborative Transplant Study (registro europeo voluntario de la actividad de trasplantes de centros de todo el mundo)

UN OS = United N etwork for O rgan Sharing (registro obligatorio de toda la actividad de trasplante realizada en Estados Unidos con apoyo económico del gobierno)

\begin{tabular}{|c|c|c|c|c|c|c|c|c|c|}
\hline \multirow[b]{2}{*}{ SUPER-VIVEN CIA } & \multicolumn{3}{|c|}{$\begin{array}{c}\text { ET } \\
\text { estimación según datos } \\
1980-2000 \\
\end{array}$} & \multicolumn{3}{|c|}{$\begin{array}{c}\text { CTS } \\
\text { estimación según datos } \\
1985-2000 \\
\end{array}$} & \multicolumn{3}{|c|}{$\begin{array}{c}\text { UNOS } \\
\text { estimación según datos } \\
1987-2000 \\
\end{array}$} \\
\hline & $\begin{array}{l}\text { Vivo } \\
\text { idéntico } \\
n=497\end{array}$ & $\begin{array}{l}\text { Vivo no } \\
\text { idéntico } \\
\text { n=3107 }\end{array}$ & $\begin{array}{l}\text { Cadáver } \\
\text { n=47015 }\end{array}$ & $\begin{array}{c}\text { Vivo } \\
\text { idéntico } \\
n=6698\end{array}$ & $\begin{array}{l}\text { Vivo no } \\
\text { idénticc } \\
n=3720\end{array}$ & $\begin{array}{l}\text { Cadáver } \\
\text { n=157328 }\end{array}$ & $\begin{array}{c}\text { Vivo } \\
\text { idéntico } \\
n=5077\end{array}$ & $\begin{array}{l}\text { Vivo no } \\
\text { idéntico } \\
\text { n=24177 }\end{array}$ & $\begin{array}{l}\text { Cadáver } \\
\text { n=87535 }\end{array}$ \\
\hline Injerto 1 año & $96,2 \%$ & $89,7 \%$ & $80,9 \%$ & $94 \%$ & $89,6 \%$ & $81,8 \%$ & $95,9 \%$ & $92,4 \%$ & $85,1 \%$ \\
\hline Injerto 5 años & $87,1 \%$ & $73,5 \%$ & $62,4 \%$ & $83,5 \%$ & $71,8 \%$ & $63,9 \%$ & $86,7 \%$ & $75,8 \%$ & $63,8 \%$ \\
\hline Paciente 1 año & $99 \%$ & $97,4 \%$ & $94,1 \%$ & $97,4 \%$ & $95,5 \%$ & $93,4 \%$ & $98,4 \%$ & $97,4 \%$ & $94,1 \%$ \\
\hline Paciente 5 años & $96 \%$ & $92,5 \%$ & $84,1 \%$ & $92,1 \%$ & $87,4 \%$ & $83,2 \%$ & $94,8 \%$ & $90,6 \%$ & $82,3 \%$ \\
\hline
\end{tabular}


fue de $86,24 \%$ a los 5 años, cuando la edad del donante era $<50$ años, y del $73,15 \%$, cuando la edad del donante era $>50$ años $(p=0.0000)$. A demás, analizaron la supervivencia tras estratificar su población según las concordancias o no de sexo entre donante y receptor, y encontraron la peor supervivencia en el grupo correspondiente a donante mujer-receptor hombre en comparación con cualquier otra combinación posible $(p=0.165)(12)$.

Según el análisis del Collaborative Transplant Study (CTS) de la evolución de los primeros trasplantes rea lizados entre los años 1985 y 2000 , la supervivencia del injerto y del paciente fue superior en el trasplante de donante vivo HLA idéntico, respecto al trasplante de donante vivo relacionado haploidéntico, y al trasplante de donante cadáver (Tabla I) (13). En el análisis del año 2004, la estimación de la supervivencia a los 20 años del primer trasplante era del 56\% para el trasplante de donante HLA idéntico con una vida media de 24,8 años, del $34 \%$ para el trasplante de donante vivo haploidéntico con una vida media de 13,5 años, y del $28 \%$ para el trasplante de donante cadáver con una vida media de 12,1 años. También en cuanto a los re-trasplantes realizados entre 1985 y 2002, el CTS apreció diferencias similares según el donante fuera vivo idéntico, vivo haploidéntico 0 cadáver: supervivencia a 20 años de $53 \%, 33 \%$ y $22 \%$ para los segundos trasplantes y de $53 \%, 25 \%$ y $15 \%$ para los terceros trasplantes. El carácter global del CTS permitió mostrar que la ventaja del trasplante renal de donante vivo persiste en diferentes contextos. Las supervivencias estimadas a 20 años para los tras-

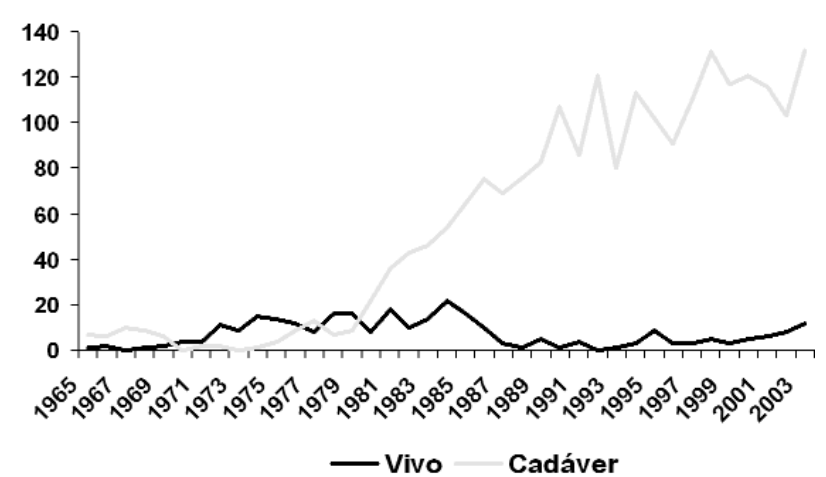

FIG URA 1. Actividad de trasplante renal en la Unidad de Trasplante Renal del Hospital Clinico de Barcelona (1965-2003) plantes renales realizados entre 1985 y 2002 de donante HLA idéntico, no idéntico y cadáver fueron de 62,43 y $32 \%$ en Europa (con vidas medias de 30,4 , 17,1 y 13,4 años), de 56,36 y $22 \%$ en Estados Unidos (con vidas medias de $24,7,13,9$ y 9,8 años) y de 53,30 y $22 \%$ en otros continentes. Los datos del CTS también demostraron la mejoría progresiva en la supervivencia del injerto a lo largo de los años en los pacientes trasplantados de donante vivo HLA idéntico (supervivencia estimada a 10 años en el periodo $1982-84,1991-93$ y $1997-99$ del $69 \%, 78$ y $85 \%$, respectivamente) y HLA haploidénticos $(44,57$ y $69 \%)$.

A lo largo de la última década, el número de trasplantes renales de donante vivo en Estados Unidos ha aumentado más de 2 veces. A esto han contribuido de manera significativa los donantes genéticamente no emparentados, fundamentalmente esposos de los receptores. Partiendo de este hecho, la división de trasplante de la Universidad de San Francisco realizó un estudio retrospectivo de cohortes, comparativo, entre los trasplantes renales de donante vivo relacionado y de donante vivo no relacionado realizados en el centro entre 1997 y 2001 (14). La incidencia de rechazo fue mayor en el trasplante renal no relacionado, sin embargo no encontraron diferencias significativas ni en la función renal a 105 años, ni en la supervivencia del injerto en ambos grupos. La incidencia de rechazo durante el primer año fue del $30 \%$ en el grupo no relacionado y del $18,5 \%$ en el grupo relacionado $(p<0,01)$. En el grupo no relacionado, el porcentaje de rechazo agudo en el primer mes fue mayor, así como el porcentaje de rechazos severos, sin embargo esto no

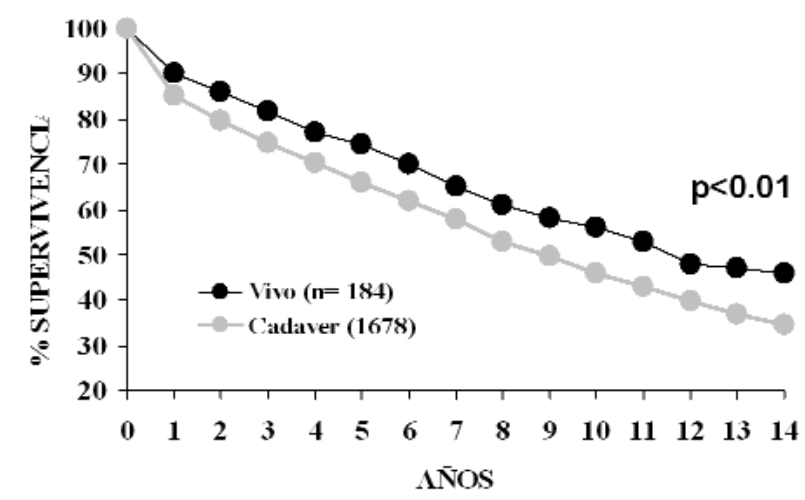

FIG URA 2.- Supervivencia comparada del injerto renal en receptores de trasplante renal de donante vivo y cadáver (1978-2002) 
afectó a la supervivencia. En el análisis multivariante, los principales factores de riesgo de rechazo durante el primer año en el trasplante renal de donante vivo relacionado fueron el retraso en la recuperación de la función del injerto y la existencia de más de una disidentidad HLA. En el grupo de donantes vivos relacionados, la ausencia de disidentidad HLA-DR se asociaba a una menor incidencia de rechazo comparado con aquellos pacientes con 102 disidentidades HLA-DR. Los factores de riesgo de rechazo agudo para los injertos de donante vivo no relacionado fueron el retraso en la recuperación de la función del injerto, la función retrasada del injerto, la edad del donante $>55$ años y el índice de masa corporal >30.

También Cecka (1), partiendo de datos de la UNOS de los años 1994-1999, estimó una excelente vida media para los injertos de donante vivo no relacionado (16,7 años) comparada con la vida media de los injertos de donante vivo relacionado idéntico, no idéntico 0 cadáver (39,2 años, 16,1 años y 10,2 años). Son, por tanto, los injertos de donantes vivos no relacionados una excelente opción para los pacientes con insuficiencia renal crónica, dado que ofrecen unos resultados comparables a los de los donantes vivos relacionados, y siempre mejores que los de los injertos de donante cadáver. Parece lógico manejar adecuadamente la inmunosupresión en estos casos, dada la mayor incidencia de rechazo en los no relacionados (14).

Por otro lado, el trasplante renal de donante vivo ofrece la posibilidad de planificar con tiempo y, en muchas ocasiones, obviar el inicio del tratamiento con diálisis. Esta opción no sólo permite disminuir morbilidad para el paciente, sino que además influye en la supervivencia del injerto. Meier-Kriesche y col. calcularon la supervivencia a 10 años de los injertos renales procedentes de donantes vivos y cadáveres según el tiempo de diálisis pre-trasplante: 75 y $69 \%$ respectivamente sin diálisis, 62 y $49 \%$ entre 0 y 6 meses de diálisis, y 49 y $39 \%$ para aquellos con más de 24 meses en diálisis. La estimación se realizó ajustando por los datos demográficos de donante y receptor, identidad HLA, isquemia fría e inmunosupresión (15).

El pool de donantes vivos está también modificándose merced a la aceptación de individuos mayores de 60 años como donantes, como ha ocurrido con el trasplante renal de donante cadáver. Giessing y col. evaluaron el impacto que los injertos de este tipo de donantes habían tenido en su centro (16). No detectaron diferencias significativas en la incidencia de rechazo durante el primer año post-trasplante, ni en la supervivencia a 1 y 5 años entre los receptores de injertos de donantes vivos $<60$ años (100 y $100 \%$ ) y $>60$ años (95 y 83\%), pero sí en la función renal al año (creatinina $1,37+0,38 \mathrm{mg} / \mathrm{dl}$ para los $<60$ años vs. $1,80+0,31 \mathrm{mg} / \mathrm{dl}$ para los $>60$ años). Concluyeron, por tanto, que este tipo de donantes son aceptables si se realiza un cuidadoso emparejamiento donante-receptor.

Por último, varios estudios recientes han tenido en cuenta la posible influencia que la nefrectomía laparoscópica podría tener en la función inicial y en la supervivencia de injerto en comparación con la nefrectomía abierta, y no han encontrado ninguna diferencia al respecto $(8,14,16)$.

\section{Nuestra experiencia}

En España, el trasplante renal de vivo apenas supone el $1 \%$ de la actividad total frente al $60 \%$ en Estados Unidos, debido probablemente a una alta tasa de donación de cadáver a lo largo de los últimos 15 años. Sin embargo en nuestro centro la actividad con donantes vivos se ha mantenido desde el inicio del programa (Figura 1 ) y ha constituido el $11 \%$ de la actividad global entre 1996 y 2003.

La experiencia de la Unidad de Trasplante Renal del Hospital Clinico de Barcelona también ha

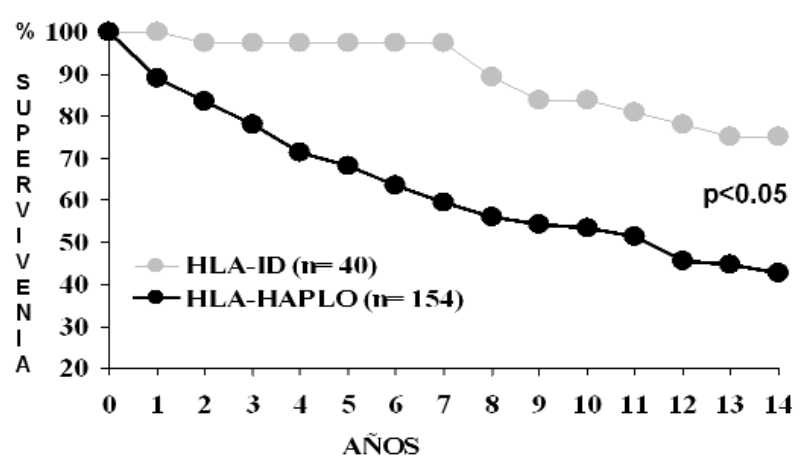

FIG URA 3. Supervivencia comparada del injerto renal en receptores de trasplante renal de vivo: HLA idénticos vs. HLA haplo-idénticos (1978-2004). 
demostrado una mejor supervivencia de injerto y receptor en el grupo de receptores de injertos de donante vivo (17). El análisis de 184 trasplantes renales de donante vivo y 1678 trasplantes renales de donante cadáver realizados entre los años 1978 y 2002 mostró que la supervivencia del injerto fue superior en el grupo de donante vivo $(p<0.01)$ (Figura 2). A su vez, la supervivencia del injerto resultó claramente mejor en los receptores de un injerto de donante vivo HLA idéntico $(n=38)$ en comparación con los receptores de un injerto HLA haploidéntico $(n=142)(p<0.05)$ (Figura 3).

Además, de acuerdo al momento histórico en que se realizaron los trasplantes, y de forma paralela a lo ocurrido con los injertos de donante cadáver, se detectaron diferencias en la supervivencia del injerto al año y a los 4 años del trasplante. La introducción de más y mejores fármacos inmunosupresores, así como un mejor manejo diagnóstico y terapéutico del rechazo agudo, la profilaxis infecciosa y el control de las complicaciones han contribuido a una mejoría en los resultados del trasplante. Así entre 1978 y 1983 la supervivencia del injerto al año fue del $89 \%$ y a los 4 años del $74,4 \%$, mientras que entre los años 1999 y 2003 la supervivencia del injerto fue del $96,6 \%$ al año y del $85,2 \%$ a los 4 años. En consonancia con lo expuesto, con el paso de los años se ha ido reduciendo de forma considerable la incidencia de rechazo agudo. Entre los años 1978 y 1983 la ausencia de rechazo agudo fue del 45,1\%, entre los años 1984 y 1998 del $57,3 \%$, y del $84,7 \%$ entre los años 1999 y 2003 .

En conclusión, todos estos resultados, que demuestran una mejor supervivencia de los injertos y receptores de trasplante renal de donante vivo en comparación con los receptores de donante cadáver, así como el bajo riesgo que supone para el donante, como se expone en otro capítulo, deben incentivar a las autoridades, a los profesionales y a los pacientes a promocionar esta alternativa terapéutica mediante una información adecuada con mayor difusión. El trasplante renal de donante vivo debe contribuir junto con el trasplante de cadáver, puesto que no son opciones excluyentes, a paliar nuestras largas listas de espera.

\section{BIBUOGRAFIA}

1. CECKA, J.M.: "The UNOS renal transplant registry." In: CECKA JM AND TERASAKI P Eds. Clinical Transplants 2000. Los Angeles. UCLA 2001.

2. NAYA, M.T.; GARRIDO, G.; CUENDE, N. y cols.: "Renal donation and transplantation in Spain 2002". Nefrologia, 23: 399, 2003.

3. Organització Catalana de Trasplantaments (OCATT). www.ocatt.net

4. BERTHOUX, F.; ABRAMOWICZ, D.; BRADLEY, B, y cols.: "European Best Practice Guidelines for Renal Transplantation". Nephrol. Dial Transplant, 15: 83, 2000.

5. COSIO, F.G.; PELLETIER, R.P.; FALKENHAIN, M.E. y cols.: "Impact of acute rejection and early allgraft function on renal allograft survival". Transplantation, 63: 1611, 1997.

6. PONTICELLI, C.; VILLA, M.; CESANA, B. y cols.: "Risk factors for late kidney allograft failure". Kidney Int., 62: 1848, 2002.

7. HARIHARAN, S.; JHONSON, C.P.; BRESNAHAN, B.A. y cols.: "Improved graft survival renal transplantation in the United States. N. Engl. J. Med., 342: 605, 2000.

8. NISHIKAWA, K.; TERASAK, I. P.I.: "Annual trends and triple therapy 1991-2000". Clinical Transplants, 247-69, 2001.

9. TAKADA, M.; NADEAU, K.C.; HANCOCK, W.W. y cols.: "Effects of explosive brain death on cytokine activation of peripheral organs in rats". Trasplantation, 65: 1533, 1998.

10. GO, K.W.; TEO, S.M.: "Comparison of patient survival between various subgroups among renal transplant patients: A single center experience". Transplant Proc., 36: 2046, 2004.

11. KIM, S.J.; LEE, H.H.; LEE, D.S. y cols.: "Prognostic factors affecting graft and patient survival in cadaveric and living kidney transplantation". Transplant Proc., 36: 2038, 2004.

12. KWON, O.J.; KWAK ,J.Y.: "The impact of sex and age matching for long-term graft survival in living donor renal transplantation." Transplant Proc., 36: 2040, 2004.

13. COLLABORATIVE TRANSPLANT STUDY. Www.ctstransplant.org

14. FULLER, T.F.; FENG, S.; BRENNAN, T.V. y cols.: "Increased rejection in living unrelated versus living related kidney transplants does not affect sort-term fuction and survival". Transplantation, 78: 1030, 2004.

15. MEIER-KRIESCHE, H.U.; KAPLAN, B.: "Waiting time on dialysis as the strongest modifiable risk factor for renal transplant outcomes: a paired donor kidney analysis". Transplantation, 74: 1377, 2002.

16. GIESSING, M.; SLOWINSKI, T.; DEGER, S. y cols.: "20-year experience with elderly donors in living renal transplantation". Transplant Proc., 35: 2855, 2003.

17. OPPENHEIMER, F.: "Trasplante de donante vivo". Manual de Trasplante Renal, M.Arias, JM. Campistol y JM. Morales editores. Grupo 2 Comunicación Médica, S. L. Madrid 2004. 